\title{
Academic Moral Tendency and Academic Ability ${ }^{*}$
}

\author{
Hansong Chen, Xuanyu Chen ${ }^{\mathrm{a}}$ and Chen Lin
}

School of Business Administration, Shandong University of Finance and Economics, Jinan 250014,
China
asys144@126.com

Keywords: Academic moral tendency; academic ability; academic atmosphere; graduate students.

\begin{abstract}
The aim of this study was to explore factors which affect academic misconduct of graduate students. After reviewing the research results of academic misconduct, we focused on relationships between academic atmosphere, academic moral tendency and academic ability of graduate students. According to data from 245 graduate students, we made an empirical test to determine the relationships. Our results show that postgraduate academic moral tendency positively impacted academic ability, as well as that academic atmosphere regulating the impact process of postgraduate academic moral tendency affecting academic ability. The results enriched the research of academic moral tendency which plays a significant role of the cultivation of graduate students' academic ability. We expect our results could make contributions to the improvement of both academic moral tendency and academic ability of graduate students.
\end{abstract}

\section{Introduction}

Graduate education is an important way to cultivate high level talents. In recent years, the number of graduate students in China has increased, and the quality of graduate education has been more and more concerned by the society. At the beginning of 2013, the Chinese Ministry of Education and other departments, aiming at improving postgraduate educational quality and deepening education reform, jointly issued the deepening the study of student opinions on education reform. This document has seven aspects of the proposed guidance, in order to enhance the postgraduate academic ability[1].

Scientific research should be based on good faith. However, with great changes in the economic and social fields, in recent years, academic misconduct began to breed. At present, the research on the graduate student's academic ethics mostly related with normative research. Less empirical research is done. The quantitative research on the academic morality is worthy of further study.

\section{Literature Review and Research Hypothesis}

\subsection{Postgraduate Academic Moral Tendency}

Academic morality is moral in academic activities for the extension of specialized content field [2]. It is the subject of academic research in the entire research process processing various interests that should be followed when a code of conduct and the standard sum [3]. It mainly relies on the scholar's conscience, community and the social morals and public opinion to implement and maintain [4]. Morality is the tendency of individuals with moral behavior which is related to the decision followed a cognitive framework, which mainly includes the utilitarian and obligation orientation two dimensions. The two dimensions are self-interest and altruism in the embodiment [5].

Different individuals have different academic moral tendency, and the existing research is mainly about the reasons of the difference. From the psychological constitution point of view, ignorance, luck, opportunistic and other negative psychological factors are driving graduate violations of academic ethics subjective willingness. In addition, the academic system is not perfect that led to the main source of academic ethics of graduate students [6].

\footnotetext{
*This paper is a stage result of Project of Shandong province graduate education innovation project(SDYY12062), Major project of social science planning and research project in Shandong Province(14AWTJ01-12), and Key Project of teaching and research teaching reform project of Shandong University of Finance and Economics(jy201411).
} 


\subsection{Academic Moral Tendency and Academic Ability of Graduate Students}

Academic ability is an important symbol to measure the level of individual academic. Overall, graduate student's academic ability mainly includes discovery and problem solving ability, literature collection and collation ability, generation and definition ability, academic proposition ability, and academic frontier sensitive. In addition, from existing research, we constructed on the theoretical framework of postgraduate academic ability culture of academic organizations. Academic ideal and attraction of student's academic ability also have a certain degree of influence [7]. And academic ideals and attractive and academic moral tendency of higher specific performance and career expectations is effect of student's academic norms of behavior important endogenous factors. Based on the above analysis, we put forward the following assumption:

Hypothesis 1 Academic moral tendency has positively impact on academic ability of graduate students. That is to say, for graduate students, the higher academic moral tendency, the higher academic ability.

\subsection{Academic Atmosphere}

Academic atmosphere is referred to the whole society and the university through a variety of academic activities which accumulated a deeper scientific theory to pursue the atmosphere. It subtly affects the work motivation of scientific research personnel, academic moral and scientific attitude. Good academic atmosphere has perfect knowledge structure, which improves the professional quality and cultivation of innovation ability of function [8]. Based on the above analysis, it can be seen that academic atmosphere is an external environmental factor which has a certain impact on academic moral tendency and academic ability of the graduate students.

Hypothesis 2 Academic atmosphere regulates the relationship between academic moral tendency and academic ability of graduate students.

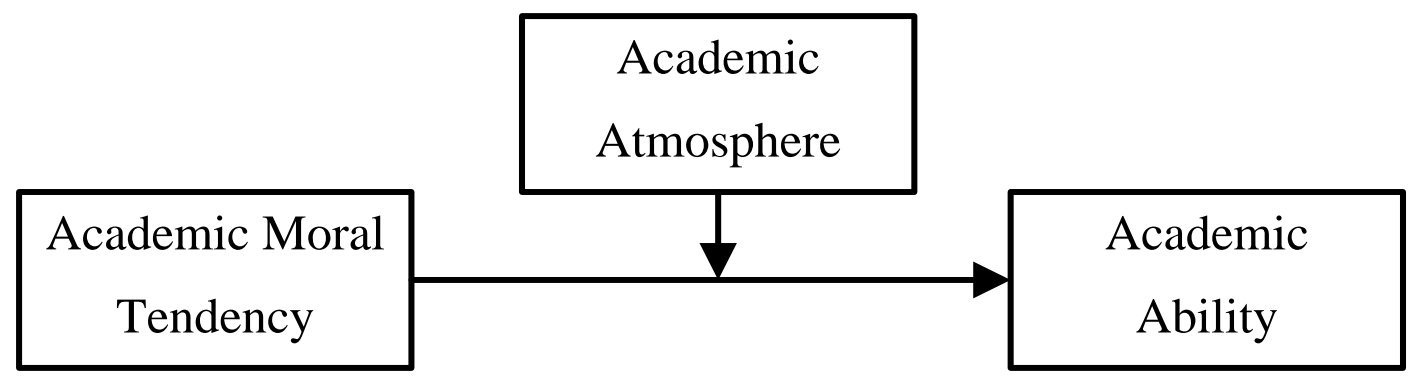

Fig. 1 Research hypothesis

\section{Research Design}

\subsection{Questionnaire Design}

Data came from postgraduate academic moral tendency and ability questionnaire survey. The questionnaire is designed by scholars from Shandong University of Finance and Economics, Anhui University of Finance and Economics and Anhui Industrial University which includes questions about age, sex, school, major, academic moral tendency, academic ability and academic atmosphere.

The measurement of academic moral tendency used to be made as direct questions and answers. There is a problem in this measurement that factors like social desirability may interfere with the validity of the data. So we examined academic moral tendency with the scenario-simulated method to improve research validity. As for academic ability and academic atmosphere, our scale was based on Higher school of philosophy and Social Sciences, academic norms (Trial). After reviewing many individual level studies, we selected age and gender as control variables.

Variables listed above, except control variables, were measured by five-level Likert scale. In order to ensure the validity of the questionnaires, we filtered the data by reverse scoring method for some items. 


\subsection{Questionnaires Collection}

The data of this study are selected from data base of Shandong University of Finance and Economics, Anhui University of Finance and Economics and Anhui Industrial University. The basic situation of the survey object is in table 1.

Table 1 Valid Sample Information

\begin{tabular}{|c|c|c|c|c|c|c|c|}
\hline & classification & number & proportion & & classification & number & proportion \\
\hline \multirow{2}{*}{ sex } & man & 96 & $39.18 \%$ & \multirow{6}{*}{ region } & Anhui & 74 & $30.20 \%$ \\
\hline & woman & 149 & $60.82 \%$ & & Shandong & 58 & $23.67 \%$ \\
\hline \multirow{4}{*}{ age } & $<21$ & 2 & $0.01 \%$ & & Jiangsu & 28 & $11.43 \%$ \\
\hline & $21 \sim 25$ & 163 & $66.53 \%$ & & Tianjin & 8 & $3.27 \%$ \\
\hline & $26 \sim 30$ & 52 & $21.22 \%$ & & Shanxi & 6 & $2.45 \%$ \\
\hline & $\geq 31$ & 28 & $12.24 \%$ & & Others & 71 & $28.98 \%$ \\
\hline
\end{tabular}

\section{Hypothesis Test and Result}

\subsection{Reliability and Validity Test}

In this study, the Cronbach's alpha coefficient of variables is all greater than 0.7 , which shows that the questionnaire has good internal reliability. In the case of KMO values and Bartlett spherical test results are allowed, rotation factor load matrix showed good convergent validity.

\subsection{Data Analysis and Results}

From table 2, we can see that the correlation coefficient between the academic moral tendency and the academic ability of the graduate students is 0.181 which means positive correlation. So hypothesis 1 was initially proved.

Table 2 Correlation Coefficient

\begin{tabular}{|c|c|c|c|c|c|c|c|}
\hline variables & 1 & 2 & 3 & 4 & 5 & mean & variance \\
\hline 1.sex & 1 & & & & & 1.607 & 0.248 \\
\hline 2.age & 0.041 & 1 & & & & 25.253 & 15.665 \\
\hline $\begin{array}{l}\text { 3.academic moral } \\
\text { tendency }\end{array}$ & 0.004 & 0.007 & 1 & & & 3.711 & 0.478 \\
\hline 4.academic atmosphere & $0.169 * *$ & 0.049 & -0.020 & 1 & & 2.726 & 0.510 \\
\hline 5.academic ability & $-0.194 * *$ & 0.020 & $0.181^{* *}$ & 0.019 & 1 & 2.852 & 0.476 \\
\hline
\end{tabular}

After multicollinearity test is qualified, we made multiple regression analysis on variables. Through the analysis of $\mathrm{R}^{2}$, regression model is valid.

Table 3 Hierarchical Regression

\begin{tabular}{cccc}
\hline & model 1 & academic ability & model2 \\
& 0.029 & 0.025 & model3 \\
\hline Age & $-0.195^{* *}$ & $-0.206^{* *}$ & 0.003 \\
Sex & & 0.061 & $-0.047^{*}$ \\
academic atmosphere & & $0.186^{* *}$ & $-0.922^{* * *}$ \\
academic moral tendency & & -0.024 \\
academic moral & & $1.334^{* * *}$ \\
tendency*academic & & \\
atmosphere & 0.038 & 0.076 & \\
$\mathrm{R}^{2}$ & $4.701^{*}$ & $4.803^{* *}$ & 0.902 \\
$\mathrm{~F}$ & 2 & 4 & $427.824^{* * *}$ \\
$\mathrm{df}$ & & Note: $:^{*}$ means $\mathrm{p}<0.05 ; * *$ means $\mathrm{p}<0.01 ; * * *$ means $\mathrm{p}<0.001$
\end{tabular}


In model 1, gender and academic ability are positively correlated, and the regression coefficient is $-0.195^{* *}$, which shows that the academic ability of male graduate students is better than that of female graduate students.

In model 2, postgraduate academic moral tendency and academic ability are positively correlated, and the correlation coefficient is $0.186^{* *}$, which shows that the academic moral tendency of the graduate students is positively related to the academic ability. So hypothesis 1 is proved.

In model 3, the regression coefficient of the interaction term is $1.334^{* * *}$, which shows that the academic atmosphere has a significant moderating effect on the relationship between academic moral tendency and academic ability. Hypothesis 2 is supported.

In order to further verify the direction and the deep influence of academic atmosphere on the moderating effects, we verified the regression coefficients of high academic atmosphere and low. The variable mean plus a standard deviation for the high group, and the mean minus one standard deviation for low grouping. The calculated regression equation is Yhigh $=-4.059+5.848 \mathrm{x}, \mathrm{Y}$ low $=-2.784+4.005 x$. The high score was significantly higher than the low score group, and the slope was positive, which showed that the academic atmosphere enhanced the positive role of the academic moral tendency of the graduate students, and further verified the hypothesis 2.

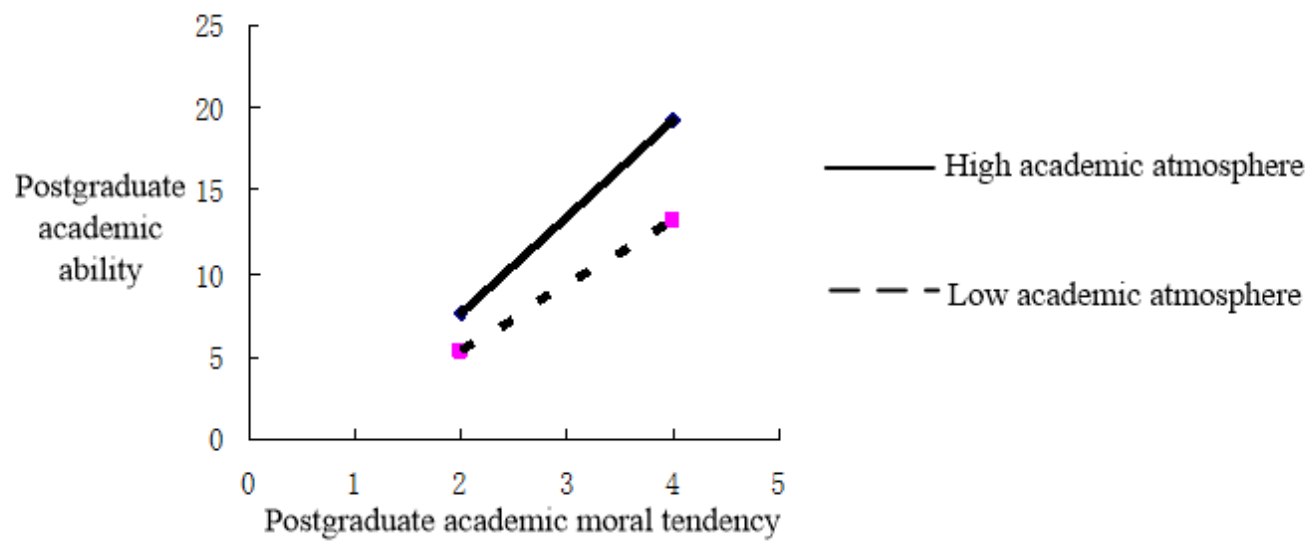

Fig. 2 The regulation function of academic atmosphere

\section{Conclusions}

In this study, 245 graduate students were regarded as the research object. By the method of multiple regression analysis, the relationship between the three academic moral tendency, academic ability and academic atmosphere is studied.

We found graduate academic moral tendency positively influenced the academic ability of graduate students. That is to say the higher academic moral tendency, the more academic behavior norms, and the more academic ability. We also found that academic atmosphere regulating the relationship between academic moral tendency and academic ability of graduate students. When the academic atmosphere is good, the influence of the graduate students' academic moral tendency on the graduate students' academic ability will be greatly affected.

How to improve the academic ability of graduate students? From a personal level, we need to fully understand the academic ethics and adhere to the bottom line of academic ethics. From the perspective of colleges and Universities, improving academic atmosphere is very important.

\section{References}

[1]. Ministry of Education, National Development and Reform Commission, Ministry of Finance on deepening the reform of graduate education [EB/OL]. 2013. (In Chinese)

[2]. Zhang Yingli, Cheng Yongjia. College students' academic moral status, psychological attribution and influence factors [J]. Education Science, 2014 (1): 69-74.(In Chinese) 
[3]. Jiang Xin Hua. Academic misconduct: a systematic analysis of academic morality in Universities [M]. Beijing: Social Science Literature Press, 2005:30.(In Chinese)

[4]. Huang Fufeng, Zong Chuanjun, Ma Xiaohui. Research on the cultivation of graduate students' academic ethics [M]. Beijing: China Social Science Press, 2012:48.(In Chinese)

[5]. Brand F N, Wheeler G E.An empirical study of ethical predispositions[J].Journal of Business Ethics,1996(9):927-940.

[6]. Jiang Xin Hua. Study on the academic morality of the graduate students: performance, origin and Countermeasures [J]. Science and Technology Management, 2003 (1): 72-76.(In Chinese)

[7]. Zhu Zhiyong, Cui Xuejuan. The academic ability of graduate students: a theoretical framework based on policy text analysis [J]. Education Research, Tsinghua University, 2012, (6): 92-99.(In Chinese)

[8]. Hu Shenghong. To create a strong academic atmosphere, and promote the quality of students to improve the quality of higher education [J]. Higher Agricultural Education, 2002 (5): 42-44.(In Chinese) 